\title{
Application of Fourier transform infrared (FTIR) spectroscopy coupled with multivariate calibration for quantitative analysis of curcuminoid in tablet dosage form
}

\author{
Chairany Siregar ${ }^{1,2}$, Sudibyo Martono ${ }^{1}$, Abdul Rohman $^{1 *}$ \\ 'Department of Pharmaceutical Chemistry, Faculty of Pharmacy, Gadjah Mada University, Yogyakarta, 55281, Indonesia. \\ ${ }^{2}$ The National Agency of Drug and Food Control, District of Samarinda, East Kalimantan, Indonesia.
}

\begin{tabular}{|c|c|}
\hline ARTICLE INFO & ABSTRACT \\
\hline $\begin{array}{l}\text { Article history: } \\
\text { Received on: } 25 / 03 / 2018 \\
\text { Accepted on: } 19 / 06 / 2018 \\
\text { Available online: } 31 / 08 / 2018\end{array}$ & $\begin{array}{l}\text { Curcuminoid, especially curcumin (CUR) and desmethoxycurcumin (DMCUR), is regarded as active components } \\
\text { of a pharmaceutical formulation containing Curcuma species responsible for several biological activities including } \\
\text { anti-inflammatory and antioxidant. The objective of this research was to validate rapid and reliable method based } \\
\text { on Fourier transform infrared (FTIR spectroscopy) in the mid-infrared region in combination with multivariate } \\
\text { analysis for quantitative analysis of curcuminoid content in tablet formulation. FTIR spectra was subjected to several }\end{array}$ \\
\hline $\begin{array}{l}\text { Key words: } \\
\text { curcumin, } \\
\text { demethoxycurcumin, PLS } \\
\text { regression, tablet, FTIR } \\
\text { spectra. }\end{array}$ & $\begin{array}{l}\text { optimizations including wavenumbers selection and derivatization to get best prediction models for the relationship } \\
\text { between actual values of curcuminoid as determined using high-performance liquid chromatography and FTIR } \\
\text { calculated values. The first derivative FTIR spectra at wavenumbers of } 2975-660 \mathrm{~cm}^{-1} \text { using partial least square } \\
\text { regression (PLSR) was preferred for quantification of CUR in tablet, while DMCUR was predicted using FTIR normal } \\
\text { spectra at wavenumbers of } 1784-1587 \mathrm{~cm}^{-1} \text {. The coefficient of determination }\left(\mathrm{R}^{2}\right) \text { values for calibration and validation } \\
\text { models either in CUR and DMCUR were of }>0.99 \text { indicating good accuracy methods. The errors in calibration } \\
\text { and validation models were low indicating the acceptable precision of the developed method. FTIR spectroscopy } \\
\text { combined with PLS regression can be used as an alternative technique for determination of CUR and DMCUR in } \\
\text { tablet dosage form. }\end{array}$ \\
\hline
\end{tabular}

\section{INTRODUCTION}

Curcuminoid, mainly curcumin (CUR) and desmethoxycurcumin (DMCUR), with chemical structures as shown in Figure 1, has been reported to have some biological activities including antioxidant, anticancer and anti-inflammatory (Rohman, 2012). Curcuminoid has been used as chemical markers during biological activity studies related to Curcuma genus. Some pharmaceutical products containing Curcuma extracts has been commercially available in Indonesian markets such as Curcuma syrup (Wahyono and Hakim, 2007), capsule, and tablet formulations (Rajashree et al., 2013). Therefore, determination

\section{${ }^{*}$ Corresponding Author}

Abdul Rohman, Department of Pharmaceutical Chemistry, Faculty of Pharmacy, Gadjah Mada University, Yogyakarta, 55281, Indonesia. E-mail:abdul_kimfar@ugm.ac.id of curcuminoid in those formulations was needed to assure the quality of curcuminoid contained in pharmaceutical products.

Chromatographic methods including chromatography with ultraviolet-visible detector (Syed et al., 2015), photo-diode array detector (Zhang and Acworth, 2013), and electrochemical detector (Long et al., 2014) has been reported for analysis of curcuminoid due to its capability to provide separation of individual curcuminoid (Siregar et al., 2017). However, chromatographic methods need more time and efforts, therefore, some simple methods based on spectroscopic methods have been introduced to overcome these obstacles. UV spectrophotometry is a method of choice for determination of curcuminoid in a formulation containing pure curcuminoid (Sharma et al., 2012), but this method is not suitable for products containing curcuminoid in plant extracts. Due to much peaks obtained to be used as variables, Fourier transforms infrared (FTIR) spectroscopy has been 
proposed for the analysis of analytes in a complex composition including curcuminoid in the extracts.<smiles>COc1cc(/C=C/C(=O)CC(=O)/C=C/c2ccc(O)c(OC)c2)ccc1O</smiles><smiles>COc1cc(/C=C/C(=O)CC(=O)/C=C/c2ccc(O)c(O)c2)ccc1O</smiles>

Fig. 1: The chemical structures of curcumin and demethoxycurcumin.

FTIR spectroscopy, based on the interaction between electromagnetic radiation currently in infrared region and samples, in combination with several chemometrics techniques, has emerged as powerful analytical tools in the pharmaceutical application (Chakraborty, 2016) due to its property as fingerprint spectra (Sim et al., 2004). In herbal medicine application, the combination of FTIR spectroscopy and chemometrics have been used for quantification of active pharmaceutical ingredients (Rohman, 2013), for discrimination between wild-grown and cultivated Ganoderma lucidum, an expensive herbal component commonly used in Chinese traditional medicine (Zhu and Tan, 2015), authentication of geographical origin of Gentiana rigescens commonly used as liver protective in traditional Chinese medicine (Wu et al., 2017) and for quality assurance of herbal medicine (Rohman et al., 2014). FTIR spectroscopy combined with partial least square and principal component regression has been used for quantification of curcuminoid in extracts of Curcuma longa (Rohman et al., 2015) and Curcuma xanthorrhiza (Lestari et al., 2017). The reported publication regarding curcuminoid analysis, so far, was in extracts or powder and using literature review, there are no reports related to the quantitative analysis of curcuminoid in tablet formulation. Therefore, in this study, FTIR spectroscopy at specific infrared region combined with multivariate calibration was optimized for quantitative analysis of curcuminoid (CUR and DMCUR).

\section{MATERIALS AND METHODS}

Curcumin (CUR) and desmethoxycurcumin (DMCUR) were isolated from commercial curcuminoid purchased from E. Merck (Darmstadt, Germany). Isolation was performed following method as described in Lestari et al. (2017). Thin Layer Chromatography (TLC) and High-Performance Liquid Chromatography (HPLC) were used to check the purity of CUR and DMCUR. The purity of CUR and DMCUR was performed using internal normalization technique. Tablet samples were purchased from several pharmacies around Yogyakarta, Indonesia. The placebo of samples was kindly given by PT. SOHO Pharmaceutical Industry (Jakarta, Indonesia).

\section{HPLC analysis}

HPLC analysis of individual curcuminoid was performed according to Siregar et al. (2017) using Shimadzu LC-20AD (Kyoto, Japan) equipped with Rheodyne $7725 \mathrm{i}$ injection valve with a $20 \mu \mathrm{L}$ loop volume and binary gradient pump. Detection was carried out Shimadzu Photodiode Array Detector (SPDM20A) operated at a wavelength of $425 \mathrm{~nm}$. Chromatographic separation was performed using Waters X-Bridge C-18 $(250 \mathrm{~mm}$ $\times 4.6 \mathrm{~mm}$ i.d; $5 \mu \mathrm{m}$ ), set at $45^{\circ} \mathrm{C}$. The mobile phase used consisted of a binary mixture of acetonitrile-acetic acid 3.00\% (49:51 v/v), delivered in an isocratic manner with flow rate arranged at 1.08 $\mathrm{mL} / \mathrm{min}$. For the preparation of a stock solution of samples, an accurately weighed amount of samples (about $200.0 \mathrm{mg}$ ) was transferred into a $25 \mathrm{~mL}$ volumetric flask, added with about 10 $\mathrm{mL}$ methanol, sonicated for $30 \mathrm{~min}$, and then diluted with mobile phase to volume. The samples were homogenized and centrifuged for $10 \mathrm{~min}$ at $10.000 \mathrm{rpm}$. A portion of sample stock solution was diluted ( 1 in $20 \mathrm{~mL}$ for CUR and 2.5 in $5 \mathrm{~mL}$ for DMCUR) with mobile phase, mixed, and then filtered using $0.45 \mu \mathrm{m}$ filter before being injected into HPLC system.



Fig. 2: HPLC chromatogram obtained during analysis of desmethoxycurcumin $\left(t_{R}\right.$ of \pm 6.28$)$ and curcumin ( $t_{R}$ of \pm 6.96$)$. For HPLC condition, see section of HPLC analysis.

\section{Preparation of calibration and validation samples}

In order to facilitate the calibration model, a tablet containing CUR and DMCUR was added with placebo with variety composition to get a different concentration of CUR and DMCUR. Multivariate calibrations of partial least square regression (PLSR) and principal component regression (PCR) were used for making calibration model. For validation samples, a set of independent samples prepared by adding a tablet with 
different composition of placebo was used. The concentration of CUR and DMCUR in validation samples was predicted using the calibration model previously built.

\section{FTIR spectroscopy analysis}

The powdered tablet samples were placed on Smart iTR ${ }^{\mathrm{TM}}$ Attenuated Total Reflectance (ATR) accessory composed of diamond crystal as sample handling technique at a controlled ambient temperature $\left(25^{\circ} \mathrm{C}\right)$. Samples were scanned using Nicolet iS10 FTIR spectrophotometer (Thermo Fisher Scientific Inc, Madison, USA) equipped with deuterated triglycine sulfate (DTGS) detector and potassium bromide $(\mathrm{KBr}) / \mathrm{Germanium}$ as a beam splitter. The instrument was connected to software OMNIC ver.9.7 and spectra were scanned at wavenumbers of 4000-650 $\mathrm{cm}^{-1}$, recorded for 32 scans at a resolution of $8 \mathrm{~cm}^{-1}$. The air spectrum was used as background. Each data point was recorded in three replicates using absorbance mode to facilitate quantitative analysis (Rohman et al., 2014).

\section{Chemometric analysis}

Multivariate analyses consisted of partial least square regression (PLSR) and principal component regression (PCR) were performed using software TQ Analyst ver.9.7 (Thermo Fisher Scientific Inc., Madison, WI) included in Nicolet iS10 FTIR instrument. PLSR and PCR were used to build a predictive model which correlated the actual values of CUR and DMCUR from HPLC determination and FTIR predicted values. Statistical parameters namely coefficient determination $\left(\mathrm{R}^{2}\right)$, Root Mean Square Error of Calibration (RMSEC) and Root Mean Square Error of Predicted (RMSEP) were computed using TQ Analyst software.

\section{RESULTS AND DISCUSSION}

HPLC, due to its capability to be used for qualitative, quantitative and preparative analyses, is a standard method for analysis of active components in herbal medicine including determination of curcumin (CUR) and desmethoxycurcumin (DMCUR) in plant extracts (Prabaningdyah et al., 2017). Figure 2 revealed HPLC chromatogram for separation and quantification of CUR and DMCUR in some tablet samples containing $C$. xanthorrhiza in its formulation. However, HPLC is timeconsuming and needs skillful analysis. Therefore, in this study, FTIR spectroscopy was developed for routine analysis of CUR and DMCUR in any pharmaceutical products. The levels of CUR and DMCUR in tablet formulation used as actual values of CUR and DMCUR were determined by HPLC using photo-diode array detector at $\lambda 425 \mathrm{~nm}$, and their results obtained were compiled in Table 1. The variation of CUR and DMCUR compositions in evaluated tablets was coming from the addition of tablets with placebo to facilitate calibration models during FTIR spectroscopic analysis.

FTIR spectra of a tablet containing extract of $C$. xanthorrhiza with curcuminoid as active components were depicted in Figure 3. Each peak was corresponding to a functional group present in two main curcuminoids present in C. xanthorrhiza, namely CUR and DMCUR (Lestari et al., 2017). The clear and broad peak at wavenumbers $(1 / \lambda)$ of $3200 \mathrm{~cm}^{-1}$ corresponded to stretching vibration of hydrogen-bonded $(-\mathrm{OH})$ present in curcuminoid, while peaks at 2950 and $2900 \mathrm{~cm}^{-1}$ originated from stretching vibrations of methyl $\left(\mathrm{CH}_{3}\right)$ and methylene $\left(\mathrm{CH}_{2}-\right)$ groups, respectively. The bending vibrations of $\mathrm{CH}_{3}$ and $\mathrm{CH}_{2}$ were also observed at $1 / \lambda 1339$ and $1423 \mathrm{~cm}^{-1}$, respectively. Conjugated carbonyl group was observed at $1 / \lambda 1655 \mathrm{~cm}^{-1}$, lower than $1 / \lambda$ in unconjugated carbonyl (Prabaningdyah et al., 2018). Table 2 compiled the functional groups responsible for IR absorption of tablet placebo spiked with Curcuma xanthorrhiza. The presence of these functional groups as indicated in each peak in FTIR spectra proved that the studied tablet contained Curcuma extract.

Table 1: The concentrations of curcumin and desmethoxycurcumin in tablet samples.

\begin{tabular}{ccc}
\hline Samples & Curcumin $(\mathbf{m g} / \mathbf{g})$ & Demethoxycurcumin $(\mathbf{m g} / \mathbf{g})$ \\
\hline Sample 1 & 0.5821 & 0.0015 \\
Sample 2 & 0.8467 & 0.0021 \\
Sample 3 & 1.0861 & 0.0026 \\
Sample 4 & 1.2279 & 0.0030 \\
Sample 5 & 1.6971 & 0.0040 \\
Sample 6 & 2.1608 & 0.0048 \\
Sample 7 & 2.5808 & 0.0060 \\
Sample 8 & 3.0433 & 0.0077 \\
Sample 9 & 3.4698 & 0.0075 \\
Sample 10 & 4.3122 & 0.0118 \\
Sample 11 & 5.1355 & 0.0134 \\
Sample 12 & 6.0553 & 0.0156 \\
Sample 13 & 6.9267 & 0.0172 \\
Sample 14 & 7.9319 & 0.0230 \\
Sample 15 & 8.6770 & 0.0247 \\
\hline
\end{tabular}

Table 2: The functional groups responsible for IR absorption of tablet placebo spiked with Curcuma xanthorrhiza (Lestari et al., 2017).

\begin{tabular}{cc}
$\begin{array}{c}\text { Wavenumbers }(\mathbf{1} / \boldsymbol{\lambda}) \\
\left(\mathbf{c m}^{-1}\right)\end{array}$ & $\begin{array}{c}\text { Functional groups along with mode of vibration } \\
3260\end{array}$ \\
2950 and 2900 & $\begin{array}{r}\text { Stretching vibration of hydrogen-bonded }(-\mathrm{OH}) \\
\text { Stretching vibrations of methyl }\left(\mathrm{CH}_{3}\right) \text { and methylene } \\
\left(\mathrm{CH}_{2}-\right) \text { groups }\end{array}$ \\
1655 & Stretching vibration of conjugated carbonyl $(\mathrm{C}=\mathrm{O})$ group \\
1423 & $\mathrm{CH}_{2}-$ bending \\
1339 & $\mathrm{CH}_{3}-$ bending \\
1259 & $\mathrm{C}-\mathrm{O}$ stretching \\
1201 & $\mathrm{C}-\mathrm{O}$ stretching \\
1140 & $\mathrm{C}-\mathrm{O}$ stretching \\
1114 & $\mathrm{C}-\mathrm{O}$ stretching \\
1017 & $\mathrm{C}-\mathrm{OH}$ stretching \\
988 & $-\mathrm{HC}=\mathrm{CH}-($ trans $)$ out of plane \\
899 & $-\mathrm{HC}=\mathrm{CH}-($ cis $)$ out of plane \\
757 & $-(\mathrm{CH})_{\mathrm{n}} ;-\mathrm{HC}=\mathrm{CH}-$ bending \\
\hline
\end{tabular}

For prediction of CUR and DMCUR, FTIR spectroscopy at specific wavenumbers was optimized by selecting certain regions of mid-infrared $\left(4000-650 \mathrm{~cm}^{-1}\right)$ capable of providing the best correlation between actual values of CUR and DMCUR as determined by HPLC and FTIR predicted values. The selection of wavenumbers regions used for prediction of CUR and 
DMCUR using FTIR spectroscopy was relied on its capability to offer the highest coefficient of determination $\left(\mathrm{R}^{2}\right)$ and lowest calibration and validation errors. To facilitate this correlation, two multivariate calibrations namely partial least square regression (PLSR) and principal component regression (PCR) were used and optimized. Table 3 compiled the performance of multivariate calibrations for prediction of CUR and DMCUR in Curcuma tablet along with statistical values, namely $\mathrm{R}^{2}$ and root mean square error of calibration (RMSEC) and error in prediction (RMSEP). The accuracy and precision of FTIR spectroscopic-multivariate calibration can be expressed by $\mathrm{R}^{2}$, RMSEC, and RMSEP. The higher $\mathrm{R}^{2}$ and the lower RMSEC and RMSEP, the better the prediction models (Sim et al., 2004).



Fig. 3: FTIR spectra of tablet placebo spiked with Curcuma xanthorrhiza containing curcumin and desmethoxycurcumin at wavenumbers of $4000-650 \mathrm{~cm}^{-1}$.

Table 3: The performance of multivariate calibration of partial least square regression (PLSR) and principle component regression (PCR) for prediction of curcumin and demethoxycurcumin in tablet formulation.

\begin{tabular}{|c|c|c|c|c|c|c|c|c|c|c|c|c|}
\hline \multirow{2}{*}{$\begin{array}{l}\text { Multivariate } \\
\text { calibration }\end{array}$} & \multirow{2}{*}{$\begin{array}{l}\text { Wavenumber } \\
\left(\mathrm{cm}^{-1}\right)\end{array}$} & \multirow{2}{*}{$\begin{array}{c}\text { Spectral } \\
\text { treatment }\end{array}$} & \multicolumn{5}{|c|}{ Curcumin } & \multicolumn{5}{|c|}{ Demethoxycurcumin } \\
\hline & & & $\begin{array}{c}\text { Number of } \\
\text { Factor }\end{array}$ & $\mathbf{R}^{2}$ calib. & RMSEC & $\mathbf{R}^{2}$ val. & RMSEP & $\begin{array}{l}\text { Number of } \\
\text { Factor }\end{array}$ & $\mathbf{R}^{2}$ & RMSEC & $\mathbf{R}^{2}$ & RMSEP \\
\hline \multirow{10}{*}{ PLSR } & $2183-993$ & Normal & 8 & 0.9874 & 0.254 & 0.9821 & 0.425 & 8 & 0.9876 & 0.000705 & 0.9811 & 0.00135 \\
\hline & $2183-993$ & 1st-der & 6 & 0.9930 & 0.191 & 0.9878 & 0.372 & 6 & 0.9938 & 0.000502 & 0.9906 & 0.000902 \\
\hline & $1784-1587$ & Normal & 5 & 0.9900 & 0.228 & 0.9928 & 0.256 & 7 & 0.9920 & 0.000565 & 0.9924 & 0.000729 \\
\hline & $1784-1587$ & 1st der & 4 & 0.9934 & 0.191 & 0.9894 & 0.332 & 5 & 0.9954 & 0.000427 & 0.9916 & 0.000754 \\
\hline & $1806-965$ & Normal & 8 & 0.9876 & 0.254 & 0.9851 & 0.391 & 10 & 0.9924 & 0.000554 & 0.9831 & 0.00113 \\
\hline & $1806-965$ & 1 st der & 6 & 0.9900 & 0.226 & 0.9862 & 0.355 & 7 & 0.9944 & 0.000472 & 0.9884 & 0.000941 \\
\hline & $\begin{array}{l}1712-653 \text { and } \\
3397-2873\end{array}$ & Normal & 9 & 0.9930 & 0.195 & 0.9986 & 0.236 & 9 & 0.9920 & 0.000585 & 0.9964 & 0.00103 \\
\hline & $\begin{array}{c}1712-653 \text { and } \\
3397-2873\end{array}$ & 1 st der. & 8 & 0.9962 & 0.144 & 0.9914 & 0.308 & 7 & 0.9940 & 0.000509 & 0.9964 & 0.00111 \\
\hline & $2975-660$ & Normal & 8 & 0.9948 & 0.168 & 0.9984 & 0.206 & 10 & 0.9962 & 0.000401 & 0.9988 & 0.000926 \\
\hline & $2975-660$ & 1st der. & 7 & 0.9968 & 0.126 & 0.9964 & 0.254 & 10 & 0.9990 & 0.000198 & 0.9974 & 0.00107 \\
\hline \multirow{8}{*}{ PCR } & $2183-993$ & Normal & 10 & 0.9779 & 0.338 & 0.9769 & 0.517 & 10 & 0.9757 & 0.000985 & 0.9841 & 0.00152 \\
\hline & 2183-993 & 1st der. & 10 & 0.9833 & 0.294 & 0.9795 & 0.488 & 10 & 0.9857 & 0.000760 & 0.9910 & 0.00108 \\
\hline & $1784-1587$ & Normal & 10 & 0.9914 & 0.212 & 0.9928 & 0.269 & 10 & 0.9914 & 0.000589 & 0.9938 & 0.000658 \\
\hline & $1784-1587$ & 1 st der & 10 & 0.9902 & 0.224 & 0.9882 & 0.315 & 10 & 0.9918 & 0.000574 & 0.9936 & 0.000640 \\
\hline & $\begin{array}{l}1712-653 \text { and } \\
3397-2873\end{array}$ & Normal & 10 & 0.9888 & 0.249 & 0.9984 & 0.246 & 10 & 0.9843 & 0.000821 & 0.9960 & 0.00117 \\
\hline & $\begin{array}{c}1712-653 \text { and } \\
3397-2873\end{array}$ & 1st der & 10 & 0.9688 & 0.415 & 0.9817 & 0.43 & 10 & 0.9657 & 0.00121 & 0.9700 & 0.0018 \\
\hline & $2975-660$ & Normal & 10 & 0.9868 & 0.263 & 0.9986 & 0.236 & 10 & 0.9817 & 0.000869 & 0.9978 & 0.00112 \\
\hline & $2975-6602$ & 1 st der & 10 & 0.9835 & 0.294 & 0.9944 & 0.323 & 10 & 0.9775 & 0.000960 & 0.9932 & 0.00156 \\
\hline
\end{tabular}




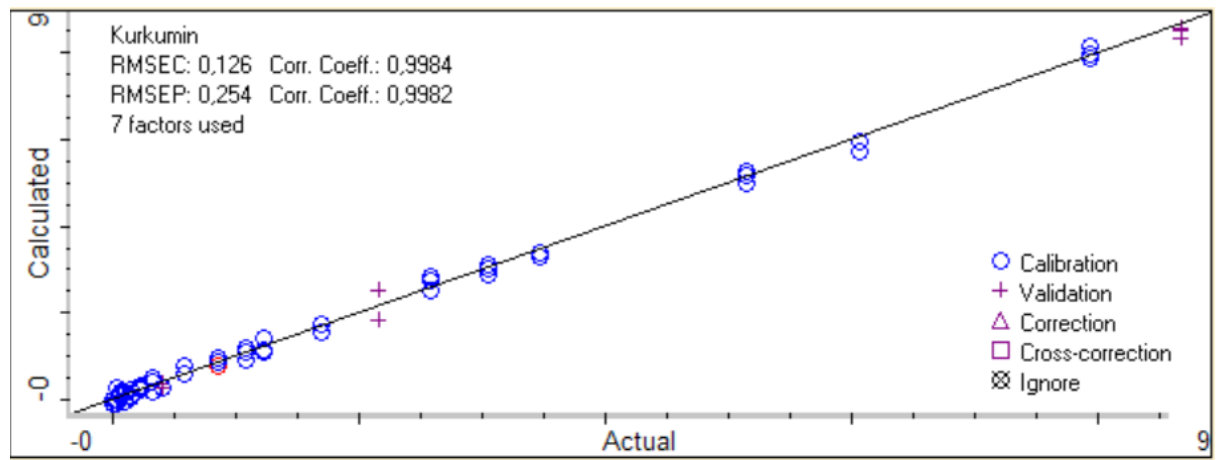

(A)

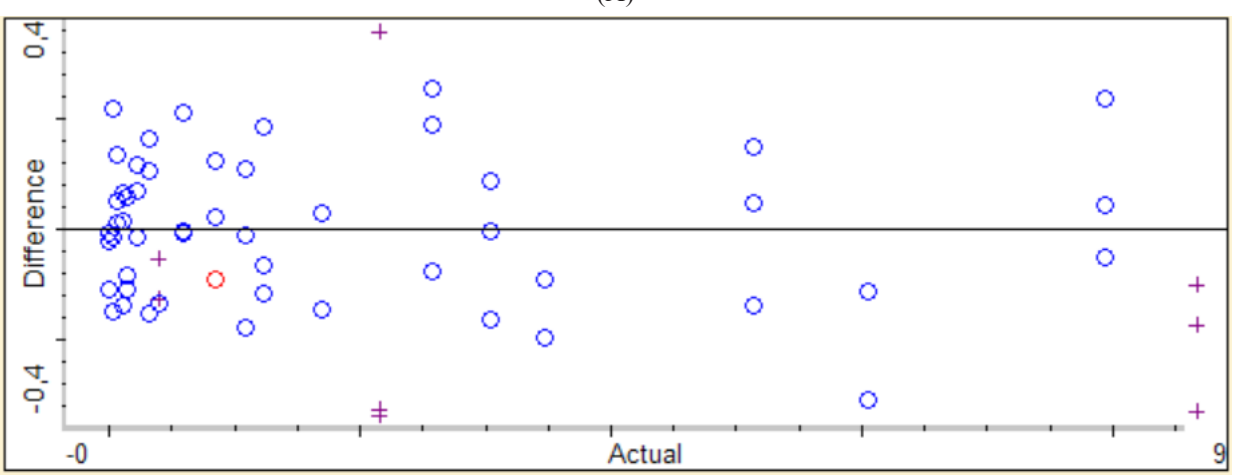

(B)

Fig. 4: The correlation between actual values of curcumin and FTIR predicted values using FTIR spectroscopy-partial least square regression (A) along with residual analysis (B).

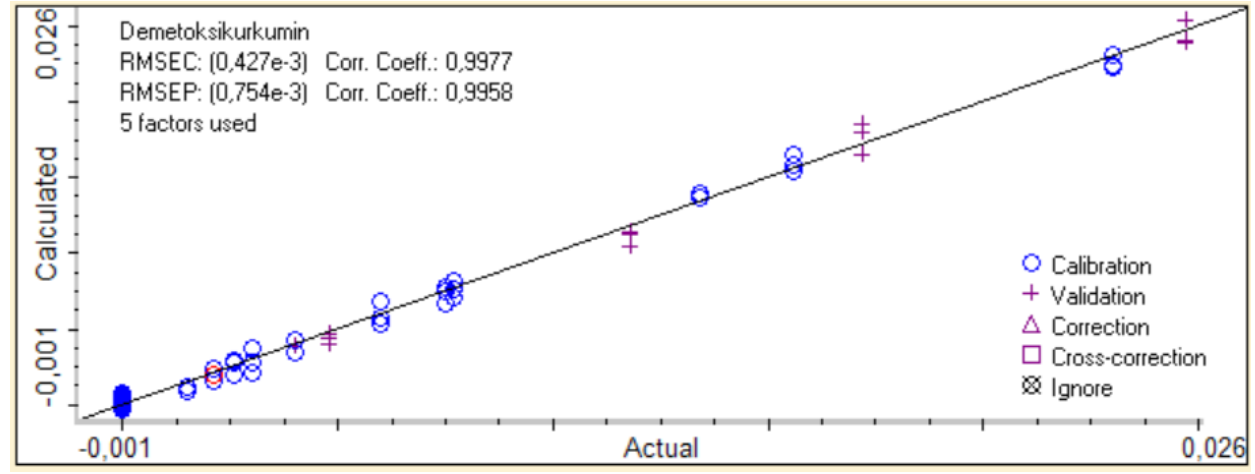

(A)



(B)

Fig. 5: The correlation between actual values of desmethoxycurcumin and FTIR predicted values using FTIR spectroscopy-partial least square regression (A) along with residual analysis (B). 
Based on the optimization using several parameters (types of multivariate calibration, wavenumbers region, spectral treatment based on normal and its first derivative), CUR was preferred to be quantified using first derivative spectra at combined wavenumbers of $2975-660 \mathrm{~cm}^{-1}$ with 7 factors. The $\mathrm{R}^{2}$ obtained for calibration and validation models for quantitative analysis of CUR using PLSR were 0.9968 and 0.9964 , with RMSEC and RMSEP values of $0.126 \%$ and $0.254 \%$, respectively. Furthermore, PLSR using wavenumbers of $1784-1587 \mathrm{~cm}^{-1}$ with 5 factors was preferred for quantification of DMCUR in a tablet with $\mathrm{R}^{2}$ values in calibration and validation of 0.9954 and 0.9916 , respectively. The RMSEC and RMSEP values obtained were of $0.000427 \%$ and $0.000754 \%$.

Figure 4 and Figure 5 revealed the correlation between actual values of CUR and DMCUR with FTIR predicted values using optimized condition assisted with PLSR along with residual analysis to evaluate the difference between actual and predicted values. From the residual analysis, it can be confirmed that residual values fall around zero (0) difference, above and below zero value. This indicated that errors occurred can be negligible. From these results, it can be concluded that FTIR spectroscopy using optimum condition can be used for prediction of CUR and DMCUR with acceptable accuracy as indicated by the high value of $\mathrm{R}^{2}$ and precision as indicated by low levels of RMSEC, RMSEP and residual values. FTIR spectroscopy in combination with chemometrics of multivariate calibration offered a fast and reliable technique for quantitative analysis of pharmaceuticals with fixed composition, however, if the placebo or matrix composition used was different, a new model calibration and validation must be developed.

\section{CONCLUSION}

FTIR spectroscopy in combination with multivariate analysis can be used as an alternative technique for quantitative analysis of CUR and DMCUR in table dosage form. The accuracy and precision of FTIR spectroscopy assisted with PLSR were acceptable. This developed method was rapid and suitable for routine analysis. However, if the composition of tablet used was different, a new model must be developed, and indeed the model was also validated.

\section{ACKNOWLEDGMENT}

The authors acknowledge to Kemenristek Dikti (the Ministry of research and higher education, Republic of Indonesia) for financial support during this study with contract number of 2328/UN1.P.III/DIT-LIT/LT/2017 awarded to Prof. Dr. Abdul Rohman. The National Agency of Drug and Food Control, District of Yogyakarta, Republic of Indonesia was acknowledged for supporting HPLC facilities that make this study possible. We also thanks PT. SOHO Pharmaceutical Industry (Jakarta, Indonesia) for supporting sample placebo.

\section{CONFLICTS OF INTEREST}

There are no conflicts of interest.

\section{REFERENCES}

Chakraborty DS. Instrumentation of FTIR and its herbal applications. World J Pharm Pharmaceutical Sci, 2016; 5(3):498-505.

Lestari HP, Martono S, Wulandari R, Rohman A. Simultaneous analysis of Curcumin and demethoxycurcumin in Curcuma xanthorrhiza using FTIR spectroscopy and chemometrics. Int Food Res J, 2017; 24(5):2097-2101.

Long Y, Zhang W, Wang F, Chen Z. Simultaneous determination of three curcuminoids in Curcuma longa L. by high performance liquid chromatography coupled with electrochemical detection. J Pharm Anal, 2014; 4(5):325-330.

Prabaningdyah NK, Riyanto S, Rohman A, Siregar C. Application of HPLC and response surface methodology for simultaneous determination of curcumin and desmethoxy curcumin in Curcuma syrup formulation. J Appl Pharm Sci, 2017; 7(12):58-64.

Prabaningdyah NK, Riyanto S, Rohman A. Application of FTIR spectroscopy and multivariate calibration for analysis of curcuminoid in syrup formulation. J Appl Pharm Sci, 2018; In Press.

Rajashree R, Divya G, Sushma P, Kanchan I, Sachin K Analytical Study of Curcumin Content in Different Dosage Forms Containing Turmeric Extract Powder and Turmeric Oleoresin Int Res J Pharm, 2013; 4(3):182-185.

Rohman A. Analysis of curcuminoids in food and pharmaceutical products. Int Food Res J, 2012; 19(1):19-27.

Rohman A. Application of Fourier Transform Infrared Spectroscopy for Quality Control of Pharmaceutical Products: a Review. Indones J Pharm, 2013; 23(1):1-8.

Rohman A, Nugroho A, Lukitaningsih E, Sudjadi. Application of vibrational spectroscopy in combination with chemometrics techniques for authentication of herbal medicine. Appl Spectrosc Rev, 2014; 49(8):603-613.

Rohman A, Sudjadi, Ramadhani D, Nugroho A. Analysis of Curcumin in Curcuma longa and Curcuma xanthorrhiza Using FTIR Spectroscopy and Chemometrics. Res J Med Plant, 2015; 9(4):179-186.

Sharma K, Agrawal SS, Gupta M. Development and validation of UV spectrophotometric method for the estimation of curcumin in bulk drug and pharmaceutical dosage forms. Int J Drug Dev Res, 2012; 4(2):375380 .

Silverstein RM, Webster FX, Kiemle DJ. 2005. Spectrometric identification of organic compounds. Hoboken, NJ: John Wiley \& Sons.

Sim C, Hamdan M, Ismail Z, Ahmad M. Assessment of Herbal Medicines by Chemometrics - Assisted Interpretation of FTIR Spectra. Anal Chim Acta, 2004; 570:1-14.

Syed HK, Bin Liew K, Loh GOK, Peh KK. Stability indicating HPLC-UV method for detection of curcumin in Curcuma longa extract and emulsion formulation. Food Chem, 2015; 170:321-326.

Siregar C, Prabaningdyah NK, Choiri S, Riyanto S, Rohman A. Optimization of HPLC Using Central Composite Design for Determination of Curcumin and Demethoxycurcumin in Tablet Dosage Form. Dhaka Univ J Pharm Sci, 2017; 16(2):137-145.

Wahyono D, Hakim AR. Effect of the curcuma plus® syrup on the pharmacokinetics of rifampicin in rats. Indonesian J Pharm, 2007; 18(4):163-168.

Wu Z, Zhao Y, Zhang J, Wang Y. Quality Assessment of Gentiana rigescens from Different Geographical Origins Using FT-IR Spectroscopy Combined with HPLC. Molecules, 2017; 22:1238.

Zhang Q, Acworth I. The quantitative analysis of curcuminoids in a food additive and foods evaluated using rapid HPLC with electrochemical, UV or fluorescence detection. Planta Med, 2013; 79:PO1.

Zhu Y, Tan ATL. Discrimination of Wild-Grown and Cultivated Ganoderma lucidum by Fourier Transform Infrared Spectroscopy and Chemometric Methods. Am J Anal Chem, 2015; 6(5):480-491.

How to cite this article:

Siregar C, Martono S, Rohman A. Application of Fourier transform infrared (FTIR) spectroscopy coupled with multivariate calibration for quantitative analysis of curcuminoid in tablet dosage form. J App Pharm Sci, 2018; 8(08): 151-156. 